\title{
(息)
}

Citation:

Gray, TG and Vickers, H and Jha, S and Jones, GL and Brown, SR and Radley, SC (2018) A systematic review of non-invasive modalities used to identify women with anal incontinence symptoms after childbirth. International Urogynecology Journal. ISSN 0937-3462 DOI: https://doi.org/10.1007/s00192-018-3819-8

Link to Leeds Beckett Repository record:

https://eprints.leedsbeckett.ac.uk/id/eprint/5577/

Document Version:

Article (Accepted Version)

The aim of the Leeds Beckett Repository is to provide open access to our research, as required by funder policies and permitted by publishers and copyright law.

The Leeds Beckett repository holds a wide range of publications, each of which has been checked for copyright and the relevant embargo period has been applied by the Research Services team.

We operate on a standard take-down policy. If you are the author or publisher of an output and you would like it removed from the repository, please contact us and we will investigate on a case-by-case basis.

Each thesis in the repository has been cleared where necessary by the author for third party copyright. If you would like a thesis to be removed from the repository or believe there is an issue with copyright, please contact us on openaccess@leedsbeckett.ac.uk and we will investigate on a case-by-case basis. 


\section{A systematic review of non-invasive modalities used to identify women with anal incontinence symptoms after childbirth}

Thomas G Gray ${ }^{1}$, Holly Vickers ${ }^{1}$, Swati Jha ${ }^{1}$, Georgina L Jones ${ }^{2}$, Steven R Brown³ ${ }^{3}$, Stephen C Radley ${ }^{1}$

1. Department of urogynaecology, Sheffield Teaching Hospitals NHS Foundation Trust, Sheffield, UK.

2. Professor of Health Psychology, Leeds Beckett University, Leeds, UK 3. Department of colorectal surgery, Sheffield Teaching Hospitals NHS Foundation Trust, Sheffield, UK.

Corresponding author: Dr. Thomas Gray

c/o Tricia Kenyon, Level 4, Jessop Wing, Tree Root Walk, Sheffield, S10 2SF, UK.

Email: Thomas.Gray@doctors.org.uk

Tel: 00447763686015

Conflicts of interest statement:

Mr. Stephen Radley is a director and shareholder of ePAQ Systems Limited, an NHS spin-out technology company, largely owned by Sheffield Teaching Hospitals NHS Foundation Trust. Mr. Radley did not collect or analyse the data included in this systematic review.

The other authors have no financial or commercial interests in ePAQ Systems Ltd or other conflicts of interest to declare.

Funding statement: No funding was received for this systematic review

Each authors contribution:

TG Gray: Project Development, Data Collection, Management and Analysis; Manuscript Writing

H Vickers: Data collection, Manuscript Editing

G.L. Jones: Methodological advice, Data analysis, Manuscript Editing

S. Jha: Project Development, Data collection, Data Analysis, Manuscript Editing

S. Brown: Data analysis, Manuscript Editing

SC Radley: Project Development, Manuscript Editing

Abstract word count: 250

Main body word count: 3414 


\section{$\underline{\text { Abstract }}$}

Aim: Anal incontinence following childbirth is prevalent and has a significant impact upon quality-of-life. Currently, there is no standard assessment for women after childbirth to identify these symptoms. This systematic review aimed to identify noninvasive modalities that have been used to identify women with anal incontinence following childbirth and assess response rates and reporting rates of anal incontinence for these modalities.

Methods: Ovid Medline, AMED, CINAHL, Cochrane Collaboration, EMBASE and Web of Science databases were searched for studies using non-invasive modalities to identify women with anal incontinence following childbirth, published from January 1966 to May 2018. Study data including type of modality, response rates and reported prevalence of anal incontinence were extracted and critically appraised.

Results: 109 studies were included from 1602 screened articles. Three types of noninvasive modality were identified: validated questionnaires/symptom scales ( $\mathrm{n}=36$ studies utilising 15 different instruments), non-validated questionnaires ( $\mathrm{n}=50$ studies) and patient interviews ( $\mathrm{n}=23$ studies). Mean response rates were $92 \%$ up to six weeks after childbirth. Non-personalised assessment modalities (validated and non-validated questionnaires) were associated with reporting of higher rates of anal incontinence compared to patient interview at all periods of follow up after childbirth, this was statistically significant between six weeks and one year after childbirth $(p<0.05)$. Conclusion: This systematic review confirms that questionnaires can be used effectively after childbirth to identify women with anal incontinence. Given the methodological limitations associated with non-validated questionnaires; the role of providing assessment for all women following childbirth using validated questionnaires 
to assess pelvic-floor symptomatology, including anal incontinence, should be considered.

Keywords: Anal incontinence, faecal incontinence, postnatal, patient reported outcomes, questionnaires

\section{Brief Summary}

This systematic review identified 14 validated patient reported outcome measures which could potentially be used routinely to identify women with anal incontinence symptoms after childbirth. 


\section{Introduction}

Anal incontinence is a common condition affecting up to $20 \%$ of adult women [1]. It has a profound and significant effect on quality of life [2] and is associated with significant healthcare costs [3]. The joint International Urogynaecological Association/International Continence Society definition of anal incontinence symptoms include faecal incontinence; defined as involuntary loss of faeces (solid and/or liquid stool) and flatus incontinence; defined as involuntary loss of flatus [4].

The main aetiological factor in the development of anal incontinence in women is childbirth; causing injury either to the anal sphincter complex, pelvic nerves or both [5]. The condition often goes unrecognised at the time of delivery and, even when managed appropriately, can lead to lasting problems, which are also frequently unreported to healthcare providers [6].

Many women may perceive anal incontinence symptoms such as flatus incontinence to be normal following childbirth and barriers to accessing care in this context include shame and embarrassment, as well as a lack of knowledge of potential treatments; many of which are minimally invasive [7]. Many general practitioners are also unaware of treatments and local care pathways for women with anal incontinence following childbirth [8]. In the UK and many other countries, there is currently no standardised assessment for women in the postnatal period to identify those who are affected by anal incontinence symptoms. This is despite a number of routine healthcare contacts during this time, including with midwives, general practitioners and health visitors; potentially yielding an opportunity for the condition to be assessed and appropriate access to care 
provided if indicated. There are a number of patient reported outcome measures and symptom scales available which could potentially be used in this context.

If women with anal incontinence symptoms are identified in a timely fashion after childbirth, there is an opportunity to offer them access to appropriate care. This may include physiotherapy and assessment in a functional bowel clinic under the care of a colorectal team with access to endoanal ultrasound scanning and manometry, followed by appropriate treatment.

The primary aim of this systematic review was to identify non-invasive modalities used to detect women with anal incontinence symptoms following childbirth. Secondary aims were comparison of response rates and prevalence rates of anal incontinence symptoms using the different types of modalities identified. It was anticipated that the non-invasive modalities would include tools such as questionnaires and patientreported outcome measures, which are increasingly used in clinical practice to identify patients with sensitive and potentially embarrassing symptoms.

\section{Methods}

This systematic review of the literature followed the PRISMA guidelines [9] and was designed to capture studies where a population of women had been studied after childbirth and a non-invasive modality or tool was used to identify anal incontinence symptoms. This systematic review was registered prospectively on the PROSPERO database (registration number: CRD42017082508). 
The study population was women following childbirth. The intervention studied was any non-invasive modality which enabled the identification of anal incontinence symptoms.

Ovid Medline, AMED, CINAHL, Cochrane library, EMBASE and Web of Science databases were searched using medical subject heading (MeSH) theme 'faecal incontinence' and the keyword 'anal incontinence' (which is not currently a MeSH theme). These were combined using Boolean AND operators with the following MeSH themes: 'prevalence', 'incidence', 'communication', 'decision making', 'surveys and questionnaires', 'access', 'pathway', 'care', 'antenatal', 'postnatal', 'computer/internet' for studies published between January 1966 and May 2018 (inclusive). Studies included were limited to adult female human subjects and were restricted to English language publications.

Conference abstracts were excluded. The rationale for restricting to English language was to identify tools suitable for use in the UK population and also because the research team lacked the language skills and resources to translate those papers published in languages other than English.

Only studies that specifically assessed women following childbirth, or studies in which this group was identified separately within the results of the study were included. The following were excluded:

- Studies assessing prevalence in community-based adults

- Studies in which women had already been identified with anal incontinence following childbirth (interventional studies including women with known incontinence after childbirth) 
- Studies which used invasive modalities, such as endoanal ultrasound or manometry

The primary outcome was the type of modality used to identify women with anal incontinence after childbirth. Secondary outcomes included response rates to the identified modalities and prevalence rates of anal incontinence reported following childbirth (including rates of incontinence to flatus, liquid stool and solid stool where reported) in order that the prevalence reported for the different types of modalities could be compared.

Two reviewers (TGG and SCR) independently reviewed all the abstracts identified by the literature search to identify papers of potential interest. All papers of potential interest to the review were obtained and read by two reviewers (TGG and HV) to identify those that were relevant. Studies were included only with the agreement of both reviewers following evaluation of full manuscripts. Any disparities were resolved by consensus and, if required, arbitration by a third reviewer (SJ). A manual search of the reference list of each manuscript was also conducted by both reviewers to identify further studies of relevance to the systematic review.

The same two reviewers independently extracted data from the included studies onto an electronic data collection form. These were compared and a summary table of consensus data was compiled. Critical appraisal of study quality was undertaken according to the principles of the STROBE statement for observational studies and Centre for Evidence Based Medicine questionnaires for cross-sectional surveys [10, 11], to assess the data quality of included studies similarly to methods used in previous comparable systematic reviews. Studies were scored out of four for data quality- one 
point being given for use of representative sampling, one point for response rate greater than $50 \%$, one point for use of a self-administered and robustly validated assessment tool (administered in its original format and language of validation and not altered by the authors of the relevant study) and one point for $95 \%$ confidence interval for the estimated prevalence of anal incontinence of no more than $2 \%$. Studies scoring $3+$ were deemed to be of high quality.

Differences in the mean prevalence of anal incontinence were compared for the different modalities identified using paired t- test. A $p$ value of less than 0.05 was considered statistically significant.

\section{$\underline{\text { Results }}$}

A total of 1602 studies (excluding any duplicates) were identified for screening with 1296 discarded on title and abstract alone. Of the remaining studies, 306 manuscripts were reviewed in full with 109 studies ultimately being included for final analysis (figure 1). A total of 80,935 women were included in this systematic review. In total 33 of the 109 studies scored three or higher for data quality ( Supplementary Tables 1, 2 and 3).

Three types of modality were used to identify anal incontinence symptoms in women following childbirth: validated patient-reported outcome measures or symptom scales (i.e. instruments that have undergone an element of psychometric testing) (36 studies-

Supplementary Table 1) [2, 12-46], non-validated questionnaires (50 studiesSupplementary Table 2) [47-96] and patient interview, both face to face and telephone (23 studies- Supplementary Table 3) [97-119]. Of the 36 studies using a validated 
patient-reported outcome measure or symptom scale, 15 different instruments were used (Table 1).

The duration of follow up in the 109 studies varied between 38 days and 34 years. Eleven studies conducted follow-up within six weeks of delivery $[12,47-49,64-66,82$, 97, 108-109], fifty two conducted follow up after six weeks and up to one year [13-21, 28-33, 40-41, 46, 50-58, 67-72, 83-86, 98-107, 110-115,119], sixteen studies conducted follow up between two and five years [22, 32, 42-45, 59-60, 73, 87-91, 94-95], and twenty six studies conducted follow up at greater than five years [2, 23-27, 33-38,61$63,74-79,92-93,116-118$ ]. Four included studies did not collect data on length of time to follow up after childbirth $[39,80-81,96]$.

Seven studies did not report response rates to the modality used to assess anal incontinence symptoms in postnatal women $[47,57,84,93$, and 99,111,119]. The mean response rate was $84 \%$ when follow up was at six weeks or less, $72 \%$ when follow up was between six weeks and one year, $70 \%$ when follow up was between two and five years and $68 \%$ when follow up was at greater than five years. Reported response rates for questionnaires and patient interviews were similar (Supplementary Table 4).

The populations of women in the studies included different characteristics, with four broadly different population types being identified: (1) Forty four studies included only primiparous women following different modes of delivery, including spontaneous vaginal delivery, instrumental delivery and caesarean section [12-27, 47-63, 97-107],) (2). Thirty seven studies included women with mixed parities and mixed modes of delivery [28-39, 64-81, 96, 108-112] (3). Twenty four studies included only women 
who had been diagnosed with obstetric anal sphincter injury (OASI) [42-45, 82-93, 113-118] (4). Four studies included only women who had undergone instrumental delivery with forceps or ventouse [46,94-95,119].

A variety of different definitions were used for anal incontinence in the studies. Generally, definitions were based on functional bowel symptom criteria or symptom severity scales. The reported rates for overall anal incontinence at different points of follow-up is shown in Table 2. Supplementary Tables 1-3 show anal incontinence prevalence for each study, including different rates for flatus incontinence, incontinence to liquid stool, incontinence to solid stool and overall anal incontinence (as per Sultan et al, 2017[4]) where reported in each study.

Overall reported rates of different types of anal and faecal incontinence varied between study populations and follow-up period. Reported prevalence of anal incontinence was higher when non-personalised assessment tools (questionnaires and patient-reported outcome measures, both validated and non-validated) were used, compared with patient interview (Table 2). There were statistically significant differences in the prevalence of anal incontinence at follow up between six weeks and one year when validated and non-validated questionnaires were used, compared to patient interview (Table 3 and 4). At all other points of follow-up there was no statistically significant difference in prevalence of anal incontinence identified by the three different noninvasive modalities (Table 3-5).

\section{Discussion}

This is an up-to-date systematic review of non-invasive modalities which have been used to identify women with anal incontinence symptoms following childbirth and is 
the first to specifically assess the tools used for this purpose; identifying fourteen validated instruments that appear to be suitable. The present systematic review has also confirms that the prevalence of anal incontinence symptoms in women following childbirth is high, affecting up to $50 \%$ of first-time mothers in the first year after childbirth in studies published in 2014 and 2016 [16,19].

The strengths of this systematic review are the rigorous search strategy employed, which has identified the relevant studies, allowing identification of the non-invasive modalities available which have been used successfully to identify women with anal incontinence after childbirth. The limitations of this systematic review include the heterogeneity in the definitions used to describe anal or faecal incontinence symptoms in the studies included, which is some cases may have underestimated the prevalence of anal incontinence. Disparity in the definition, or lack of definition, of what constitutes obstetric anal sphincter injury may also have contaminated the results. The use of non-validated questionnaires and patient interviews (supplementary tables 2 and 3) may have also resulted in over or under-reporting of anal incontinence symptoms. The small numbers of studies for the three different non-invasive modalities at various different points of follow-up may have resulted in type 2 statistical errors when comparing prevalence rates using paired $t$ test. The use of a search strategy which excluded papers not published in English may have also resulted in missing non-invasive modalities potentially relevant to this systematic review.

Whilst there was a degree of heterogeneity in the definitions used to report anal incontinence in the studies included in this review, these definitions were based on functional bowel symptom criteria or symptom severity scales. Some studies had 
sought to only assess faecal incontinence (excluding flatus incontinence), potentially underestimating anal incontinence rates, and some had reported as 'faecal incontinence' rates which actually included flatus incontinence. When extracting data from all papers, the current IUGA/ICS definition of anal incontinence [4] was used (supplementary tables 1, 2 and 3). Flatus incontinence is the most common symptom in the spectrum of anal incontinence. Frank faecal incontinence of liquid or solid stool is less common, but has a greater impact on quality of life [120]. However, studies assessing patient preferences for end points in anal incontinence treatment have indicated that flatus incontinence, faecal frequency and faecal urgency are among the most bothersome symptoms, having a significant impact on quality of life [121] and are therefore it is important to include and assess for flatus incontinence in addition to faecal incontinence.

A number of studies $(n=31)$ in this systematic review were published before Sultan's classification system for obstetric anal sphincter injury (OASI) was published and became well established in clinical practice [122]. The populations identified in this systematic review include studies which may contain a larger number of patients with either unrecognised or inadequately repaired third or fourth degree perineal tears, resulting in a higher rate of anal incontinence symptoms than would be expected with current practices. However, the reported rates of third and fourth degree perineal tears (obstetric anal sphincter injury) have actually risen in the last ten years $[123,124]$. This has previously been attributed in part to increased detection and reporting of third and fourth degree tears, however, this is also now considered to be due to inconsistencies in preventing OASI in different units, inconsistencies in midwifery and obstetric training and skills, lack of awareness of risk factors and the long-term impact of OASI and 
variations in practice between midwives and obstetricians [124]. Measures to help reverse this trend are being put in place with a current trial of a national care bundle devised by the Royal College of Obstetricians and Gynaecologists (UK) and supported by the Royal College of Midwives (UK) [125], which makes use of the increasing evidence for specific manual perineal protection maneuvers [126]. It is clear that women are currently at risk of anal incontinence following childbirth and there is currently a lack of interventions to identify such affected women following childbirth and help them to access care and treatment.

The type of modality used (validated questionnaire/symptom scale, non-validated questionnaire and patient interview) was shown to be a significant factor in the reported prevalence of anal incontinence symptoms in studies included in this systematic review (Table 2). Lower rates of anal incontinence symptoms were observed when personalised data collection methods (face to face interview or telephone interview) were used, compared with non-personalised self-completed questionnaires (both validated and non-validated)(Tables 2-5). This was demonstrated at both short and long-term periods of follow up (Table 2) and was statistically significant at the six weeks to one year follow-up period (Tables 3 and 4). This finding mirrors those of systematic reviews of the prevalence of faecal incontinence [1] where reporting of faecal incontinence symptoms was found to be lower when face-to-face and telephone interviews were used to assess these embarrassing symptoms, when compared to self-completed questionnaires. Differences in the prevalence rates of anal incontinence between the different modalities did not reach statistical significance at the other points of follow up. This may be due to a type two statistical error due to the small sample sizes for these periods of follow up, compared to the six week-one year 
follow up period where the sample sizes were large enough to demonstrate a statistically significant effect.

It has previously been shown that using non-personalised methods (self-completed questionnaires), which may be perceived as less intimidating, results in increased rates of disclosure for urinary incontinence compared to patient interview $[127,128]$. We would anticipate that this would also be the case for reporting of anal incontinence symptoms.

Two of the main barriers to accessing care for faecal incontinence in a recently published, well-designed qualitative study were embarrassment and stigma which were manifested as deeply felt shame in violating a social taboo to not talk about bowel symptoms [7]. This is often compounded by normative thinking, with patients feeling that faecal incontinence may be a normal symptom following childbirth and a lack of knowledge about the condition and fear of investigation or treatment. Therefore, many women living with anal incontinence symptoms after childbirth may not seek healthcare. This is despite a number of healthcare contacts during the post-natal period, such as routine postnatal follow up, infant vaccinations and development assessments; which lead to interactions with healthcare professionals including midwives, health visitors and general practitioners. These contacts present a number of opportunities where a self-completed questionnaire could be administered routinely to identify women with anal incontinence symptoms; potentially enabling access to care for affected women. The relatively high response rates to the modalities evaluated in this systematic review (Table 1) suggest that using an appropriate questionnaire to assess 
pelvic floor symptoms, including anal incontinence in the first year after childbirth would result in good response rates in clinical practice.

The fifteen validated patient-reported outcome measures/symptom scales identified by this systematic review have all undergone psychometric testing in populations of women with anal incontinence. The comparison of psychometric properties of these instruments is outside the scope of this systematic review. Fourteen of these tools would appear to be suitable for identifying anal incontinence symptoms following childbirth. The Faecal Incontinence Quality of Life (FIQoL) questionnaire [129] is used to assess health related quality of life in patients previously identified as having faecal incontinence, rather than as a means to identify those with the symptom and is therefore not suitable for administration to women following childbirth, unless they are known to have anal incontinence.

The Jorge and Wexner score [5], Vaizey incontinence score [130], Colorectal Anal Distress Inventory [131], Danish Anal Sphincter Rupture Questionnaire [132], St Mark's Score [133], Park's score [134], Bowel Symptom questionnaire[135],Fecal Incontinence questionnaire [136] , Anal Incontinence score [137] and Manchester Health Questionnaire [138](now modified Manchester Health questionnaire [139]) are all paper-based instruments which assess anal incontinence and bowel symptoms. The Australian Pelvic Floor Questionnaire [140], Epidemiology of Prolapse and Incontinence Questionnaire [141] and the Personal Assessment Questionnaire (PAQ) [142] are comprehensive pelvic-floor questionnaires which are also paper-based, assessing prolapse, vaginal symptoms and urinary incontinence in addition to anal 
incontinence symptoms. The Personal Assessment Questionnaire (PAQ) [142] has subsequently been further validated in an electronic format (ePAQ) [143]. The validated questionnaires in this systematic review were administered to populations including ten different languages (Supplementary Table 1). All of the identified instruments had been previously validated in the language in which they were used for in this study. The majority of the symptom scales and validated questionnaires identified in this systematic review have also been validated in translated forms into multiple languages (Table 1).

When using patient reported outcome measures including questionnaires and symptom scales, it is important to use instruments that are psychometrically robust with evidence of their validity, reliability and functionality. This reduces bias and ensures the validity of results. Studies which use questionnaires that have not been validated for use in the population of interest may potentially be subject to measurement error and lack ability to measure changes in health status accurately [144]. Therefore, any conclusions drawn cannot be made with confidence. Where a validated instrument is available, it should be used in preference to a non-validated instrument.

In conclusion, this systematic review has identified three types of non-invasive modality which can be used to identify women with anal incontinence following childbirth. The key clinical message is that using non-personalised assessment methods (validated and non-validated questionnaires/symptom scales) is likely to be more effective than patient interview when assessing intimate and embarrassing symptoms such as anal incontinence; which is a prevalent symptom following childbirth, with a significant potential for impact on health related quality of life. 
Therefore, the role of a national standard assessment for all women following childbirth using validated questionnaires to assess for pelvic floor symptoms, including anal incontinence, should be considered. Validated questionnaires and symptoms scales should be used in preference to non-validated tools owing to the methodological limitations of using non-validated instruments. Further psychometric validation of the validated measures identified in this systematic review is required, in populations of postnatal women, before recommending their use as part of routine clinical practice in this context. The value and cost of using appropriate validated tools to identify affected women, and subsequently providing access to care and support, also warrants further research.

\section{Acknowledgements}

The researchers would like to acknowledge the MASIC Foundation and Professor Michael Keighley for providing the impetus for this systematic review and further planned program of research and service delivery on this subject. 


\section{$\underline{\text { References }}$}

1. Sharma A, Yuan L, Marshall RJ, Merrie AE, Bissett IP. Systematic review of the prevalence of faecal incontinence. British Journal of Surgery. 2016;103:1589-1597.

2. Samarasekera DN, Bekhit MT, Wright Y, Lowndes RH, Stanley KP, Preston JP, Preston P, Speakman CT. Long-term anal continence and quality of life following postpartum anal sphincter injury. Colorectal Disease. 2008;10(8):793-9.

3. Mellgren A, Jensen LL, Zetterström JP, Wong WD, Hofmeister JH, Lowry AC. Longterm cost of fecal incontinence secondary to obstetric injuries. Diseases of the Colon \& Rectum. 1999;42(7):857-65.

4. Sultan AH, Monga A, Lee J, Emmanuel A, Norton C, Santoro G, Hull T, Berghmans B, Brody S, Haylen BT. An International Urogynecological Association (IUGA)/International Continence Society (ICS) joint report on the terminology for female anorectal dysfunction. Neurourology and Urodynamics. 2017;36(1):10-34.

5. Jorge JM, Wexner SD. Etiology and management of fecal incontinence. Diseases of the Colon \& Rectum. 1993;36(1):77-97.

6. Brown HW, Wexner SD, Lukacz ES. Factors associated with care seeking among women with accidental bowel leakage. Female Pelvic Medicine \& Reconstructive Surgery. 2013;19(2):66-71. 
7. Brown HW, Rogers RG, Wise ME. Barriers to seeking care for accidental bowel leakage: a qualitative study. International Urogynecology Journal. 2017;28(4):543551.

8. Thekkinkattil DK, Lim M, Finan PJ, Sagar PM, Burke D. Awareness of investigations and treatment of faecal incontinence among the general practitioners: a postal questionnaire survey. Colorectal Disease. 2008;10(3):263-267.

9. Liberati A, Altman DG, Tetzlaff J, Mulrow C, Gøtzsche PC, Ioannidis JP, Clarke M, Devereaux PJ, Kleijnen J, Moher D. The PRISMA statement for reporting systematic reviews and meta-analyses of studies that evaluate health care interventions: explanation and elaboration. PLoS medicine. 2009;6(7):e1000100.

10. Von Elm E, Altman DG, Egger M, Pocock SJ, Gøtzsche PC, Vandenbroucke JP, Strobe Initiative. The Strengthening the Reporting of Observational Studies in Epidemiology (STROBE) Statement: guidelines for reporting observational studies. International Journal of Surgery. 2014;12(12):1495-9.

11. Munn Z, Moola S, Riitano D, Lisy K. The development of a critical appraisal tool for use in systematic reviews addressing questions of prevalence. International journal of health policy and management. 2014;3(3):123.

12. Fynes M, Donnelly VS, O’Connell PR, O’Herlihy C. Cesarean delivery and anal sphincter injury. Obstetrics \& Gynecology. 1998;92(4):496-500.

13. Solans-Domènech $M$, Sánchez E, Espuña-Pons M. Urinary and anal incontinence during pregnancy and postpartum: incidence, severity, and risk factors. Obstetrics \& Gynecology. 2010 Mar 1;115(3):618-28.

14. Frudinger A, Halligan S, Bartram CI, Spencer J, Kamm MA, Winter R. Assessment of the predictive value of a bowel symptom questionnaire in identifying perianal and 
anal sphincter trauma after vaginal delivery. Diseases of the colon \& rectum. 2003;46(6):742-7.

15. Donnelly V, Fynes M, Campbell D, Johnson H, O’Connell PR, O’Herlihy C. Obstetric events leading to anal sphincter damage. Obstetrics \& Gynecology. 1998;92(6):955961.

16. Rogers RG, Leeman LM, Borders N, Qualls C, Fullilove AM, Teaf D, Hall RJ, Bedrick E, Albers LL. Contribution of the second stage of labour to pelvic floor dysfunction: a prospective cohort comparison of nulliparous women. BJOG: An International Journal of Obstetrics \& Gynaecology. 2014;121(9):1145-54.

17. Hatem M, Pasquier JC, Fraser W, Lepire E. Factors associated with postpartum urinary/anal incontinence in primiparous women in Quebec. Journal of obstetrics and gynaecology Canada. 2007;29(3):232-9.

18. Leeman L, Rogers R, Borders N, Teaf D, Qualls C. The effect of perineal lacerations on pelvic floor function and anatomy at 6 months postpartum in a prospective cohort of nulliparous women. Birth. 2016;43(4):293-302

19. Johannessen H, Wibe A, Stordahl A, Sandvik L, Backe B, Mørkved S. Prevalence and predictors of anal incontinence during pregnancy and 1 year after delivery: a prospective cohort study. BJOG: An International Journal of Obstetrics \& Gynaecology. 2014;121(3):269-80.

20. Chan SS, Cheung RY, Yiu KW, Lee LL, Chung TK. Prevalence of urinary and fecal incontinence in Chinese women during and after their first pregnancy. International urogynecology journal. 2013;24(9):1473-9.

21. Durnea CM, Khashan AS, Kenny LC, Tabirca SS, O’Reilly BA. The role of prepregnancy pelvic floor dysfunction in postnatal pelvic morbidity in primiparous women. International urogynecology journal. 2014;25(10):1363-74. 
22. Gartland D, MacArthur C, Woolhouse H, McDonald E, Brown SJ. Frequency, severity and risk factors for urinary and faecal incontinence at 4 years postpartum: a prospective cohort. BJOG: An International Journal of Obstetrics \& Gynaecology. 2016;123(7):1203-11.

23. Damon H, Bretones S, Henry L, Mellier G, Mion F. Long-term consequences of first vaginal delivery-induced anal sphincter defect. Diseases of the colon \& rectum. 2005:48(9):1772-6.

24. Evers EC, Blomquist JL, McDermott KC, Handa VL. Obstetrical anal sphincter laceration and anal incontinence 5-10 years after childbirth. American Journal of Obstetrics \& Gynecology. 2012;207(5):425-e1.

25. Dolan LM, Hilton P. Obstetric risk factors and pelvic floor dysfunction 20 years after first delivery. International urogynecology journal. 2010;21(5):535-544.

26. Nilsson I, Åkervall S, Milsom I, Gyhagen M. Long-term effects of vacuum extraction on pelvic floor function: a cohort study in primipara. International urogynecology journal. 2016;27(7):1051-6.

27. Gyhagen M, Bullarbo M, Nielsen TF, Milsom I. The prevalence of urinary incontinence 20 years after childbirth: a national cohort study in singleton primiparae after vaginal or caesarean delivery. BJOG: An International Journal of Obstetrics \& Gynaecology. 2013;120(2):144-51

28. Soligo M, Livio S, De Ponti E, Scebba I, Carpentieri F, Serati M, Ferrazzi E. Pelvic floor assessment after delivery: how should women be selected?. European Journal of Obstetrics \& Gynecology and Reproductive Biology. 2016;206:153-7.

29. Torrisi G, Minini G, Bernasconi F, Perrone A, Trezza G, Guardabasso V, Ettore G. A prospective study of pelvic floor dysfunctions related to delivery. European Journal of Obstetrics \& Gynecology and Reproductive Biology. 2012;160(1):110-115. 
30. Pinta TM, Kylänpää ML, Teramo KA, Luukkonen PS. Sphincter rupture and anal incontinence after first vaginal delivery. Acta obstetricia et gynecologica Scandinavica. 2004;83(10):917-22.

31. Guise JM, Morris C, Osterweil P, Li H, Rosenberg D, Greenlick M. Incidence of fecal incontinence after childbirth. Obstetrics \& Gynecology. 2007;109(2, Part 1):281-8.

32. Wagenius J, Laurin J. Clinical symptoms after anal sphincter rupture: a retrospective study. Acta obstetricia et gynecologica Scandinavica. 2003;82(3):246-50.

33. Mous M, Muller SA, De Leeuw JW. Long-term effects of anal sphincter rupture during vaginal delivery: Faecal incontinence and sexual complaints. BJOG: An International Journal of Obstetrics \& Gynaecology. 2008;115(2):234-8.

34. Baud D, Meyer S, Vial Y, Hohlfeld P, Achtari C. Pelvic floor dysfunction 6 years postanal sphincter tear at the time of vaginal delivery. International urogynecology journal. 2011;22(9):1127-34.

35. Handa VL, Blomquist JL, Knoepp LR, Hoskey KA, McDermott KC, Muñoz A. Pelvic floor disorders 5-10 years after vaginal or cesarean childbirth. Obstetrics and gynecology. 2011;118(4):777.

36. Altman D, Ekström Å, Forsgren C, Nordenstam J, 1993erström J. Symptoms of anal and urinary incontinence following cesarean section or spontaneous vaginal delivery. American Journal of Obstetrics \& Gynecology. 2007;197(5):512-e1

37. Faltin DL, Otero M, Petignat $P$, Sangalli MR, Floris LA, Boulvain M, Irion O. Women's health 18 years after rupture of the anal sphincter during childbirth: I. Fecal incontinence. American Journal of Obstetrics \& Gynecology. 2006;194(5):1255-9.

38. Soerensen MM, Buntzen S, Bek KM, Laurberg S. Complete obstetric anal sphincter tear and risk of long-term fecal incontinence: a cohort study. Diseases of the Colon \& Rectum. 2013;56(8):992-1001. 
39. Fritel X, Ringa V, Varnoux N, Zins M, Bréart G. Mode of delivery and fecal incontinence at midlife: a study of 2,640 women in the Gazel cohort. Obstetrics \& Gynecology. 2007;110(1):31-8.

40. Vaccaro C, Clemons JL. Anal sphincter defects and anal incontinence symptoms after repair of obstetric anal sphincter lacerations in primiparous women. International Urogynecology Journal. 2008;19(11):1503-8.

41. Andrews V, Thakar R, Sultan AH. Outcome of obstetric anal sphincter injuries (OASIS)—role of structured management. International Urogynecology Journal. 2009;20(8):973.

42. Norderval S, Nsubuga D, Bjelke C, Frasunek J, Myklebust I, Vonen B. Anal incontinence after obstetric sphincter tears: incidence in a Norwegian county. Acta obstetricia et gynecologica Scandinavica. 2004;83(10):989-94.

43. Richter HE, Nager CW, Burgio KL, Whitworth R, Weidner AC, Schaffer J, Zyczynski HM, Norton P, Jelovsek JE, Meikle SF, Spino C. Incidence and predictors of anal incontinence after obstetric anal sphincter injury in primiparous women. Female pelvic medicine \& reconstructive surgery. 2012;21(4):182.

44. Tin RY, Schulz J, Gunn B, Flood C, Rosychuk RJ. The prevalence of anal incontinence in post-partum women following obstetrical anal sphincter injury. International urogynecology journal. 2010;21(8):927-32.

45. Jangö H, Langhoff-Roos J, Rosthøj S, Sakse A. Mode of delivery after obstetric anal sphincter injury and the risk of long-term anal incontinence. American Journal of Obstetrics \& Gynecology. 2016;214(6):733-e1.

46. Fitzpatrick M, Behan M, O'Connell PR, O'Herlihy C. Randomised clinical trial to assess anal sphincter function following forceps or vacuum assisted vaginal delivery. BJOG: an international journal of obstetrics \& gynaecology. 2003;110(4):424-429. 
47. Rieger N, Schloithe A, Saccone G, Wattchow D. A prospective study of anal sphincter injury due to childbirth. Scandinavian journal of gastroenterology. 1998 Jan 1;33(9):950-955.

48. Zetterström J, Mellgren A, Jensen LL, Wong WD, Kim DG, Lowry AC, Madoff RD, Congilosi SM. Effect of delivery on anal sphincter morphology and function. Diseases of the colon \& rectum. 1999;42(10):1253-1260.

49. Donnelly VS, O'herlihy C, Campbell DM, O'Connell PR. Postpartum fecal incontinence is more common in women with irritable bowel syndrome. Diseases of the colon \& rectum. 1998;41(5):586-589.

50. Faltin DL, Sangalli MR, Roche B, Floris L, Boulvain M, Weil A. Does a second delivery increase the risk of anal incontinence?. BJOG: An International Journal of Obstetrics \& Gynaecology. 2001;108(7):684-688.

51. Chaliha C, Sultan AH, Bland JM, Monga AK, Stanton SL. Anal function: effect of pregnancy and delivery. American journal of obstetrics and gynecology. 2001;185(2):427-432.

52. Faltin DL, Boulvain M, Irion O, Bretones S, Stan C, Weil A. Diagnosis of anal sphincter tears by postpartum endosonography to predict fecal incontinence. Obstetrics \& Gynecology. 2000;95(5):643-647.

53. Hatem M, Pasquier JC, Fraser W, Lepire E. Factors associated with postpartum urinary/anal incontinence in primiparous women in Quebec. Journal of obstetrics and gynaecology Canada. 2007;29(3):232-239.

54. Fenner DE, Genberg B, Brahma P, Marek L, DeLancey JO. Fecal and urinary incontinence after vaginal delivery with anal sphincter disruption in an obstetrics unit in the United States. American journal of obstetrics and gynecology. 2003;189(6):1543-1549. 
55. Zetterstrom JP, López A, Anzén BO, Dolk A, Norman M, Mellgren A. Anal incontinence after vaginal delivery: a prospective study in primiparous women. BJOG: An International Journal of Obstetrics \& Gynaecology. 1999;106(4):324-330.

56. van Brummen HJ, Bruinse HW, van de Pol G, Heintz AP, van der Vaart CH. Defecatory symptoms during and after the first pregnancy: prevalences and associated factors. International Urogynecology Journal. 2006;17(3):224-30.

57. Brown SJ, Gartland D, Donath S, MacArthur C. Fecal incontinence during the first 12 months postpartum: complex causal pathways and implications for clinical practice. Obstetrics \& Gynecology. 2012;119(2):240-9.

58. Svare JA, Hansen BB, Lose G. Prevalence of anal incontinence during pregnancy and 1 year after delivery in a cohort of primiparous women and a control group of nulliparous women. Acta obstetricia et gynecologica Scandinavica. 2016;95(8):920-5.

59. Koops SS, Vervest HA, Oostvogel HJ. Anorectal symptoms after various modes of vaginal delivery. International Urogynecology Journal. 2003;14(4):244-249.

60. Pollack J, Nordenstam J, Brismar S, Lopez A, Altman D, Zetterstrom J. Anal incontinence after vaginal delivery: a five-year prospective cohort study. Obstetrics \& Gynecology. 2004;104(6):1397-402.

61. Nordenstam J, Altman D, Brismar S, Zetterström J. Natural progression of anal incontinence after childbirth. International Urogynecology Journal. 2009 Sep $1 ; 20(9): 1029-35$.

62. Gyhagen M, Åkervall S, Milsom I. Clustering of pelvic floor disorders 20 years after one vaginal or one cesarean birth. International urogynecology journal. 2015;26(8):1115-21. 
63. Halle TK, Salvesen KÅ, Volløyhaug I. Obstetric anal sphincter injury and incontinence 15-23 years after vaginal delivery. Acta obstetricia et gynecologica Scandinavica. 2016;95(8):941-7.

64. Rajeshkannan N, Pathmeswaran A. Prevalence of postpartum anal incontinence: a cross sectional study in Northern Sri Lanka. Ceylon Medical Journal. 2013;58(2).

65. Hall W, McCracken K, Osterweil P, Guise JM. Frequency and predictors for postpartum fecal incontinence. American journal of obstetrics and gynecology. 2003;188(5):1205-1207.

66. Abramowitz L, Sobhani I, Ganansia R, Vuagnat A, Benifla JL, Darai E, Madelenat P, Mignon M. Are sphincter defects the cause of anal incontinence after vaginal delivery? Diseases of the Colon \& Rectum. 2000;43(5):590-596.

67. Hannah ME, Hannah WJ, Hodnett E, Chalmers B, Kung R, Willan A, Amankwah K, Cheng M, Helewa M, Hewson S, Saigal S, Whyte H, Gafni A. Outcomes at 3 months after planned cesarean vs planned vaginal delivery for breech presentation at term: the international randomized Term Breech Trial. JAMA. 2002;287(14):1822-1831.

68. Haadem K, Dahlström JA, Lingman G. Anal sphincter function after delivery: a prospective study in women with sphincter rupture and controls. European Journal of Obstetrics \& Gynecology and Reproductive Biology. 1990;35(1):7-13.

69. MacArthur C, Glazener CM, Wilson PD, Herbison GP, Gee H, Lang GD, Lancashire R. Obstetric practice and faecal incontinence three months after delivery. BJOG: An International Journal of Obstetrics \& Gynaecology. 2001;108(7):678-683.

70. Eason E, Labrecque M, Marcoux S, Mondor M. Anal incontinence after childbirth. Canadian Medical Association Journal. 2002;166(3):326-30. 
71. Obioha KC, Ugwu EO, Obi SN, Dim CC, Oguanuo TC. Prevalence and predictors of urinary/anal incontinence after vaginal delivery: prospective study of Nigerian women. International urogynecology journal. 2015;26(9):1347-54.

72. Glazener CM, Abdalla M, Stroud P, Templeton A, Russell IT, Naji S. Postnatal maternal morbidity: extent, causes, prevention and treatment. BJOG: An International Journal of Obstetrics \& Gynaecology. 1995;102(4):282-7.

73. Palm A, Israelsson L, Bolin M, Danielsson I. Symptoms after obstetric sphincter injuries have little effect on quality of life. Acta obstetricia et gynecologica Scandinavica. 2013;92(1):109-15.

74. Ryhammer AM, Bek KM, Laurberg S. Multiple vaginal deliveries increase the risk of permanent incontinence of flatus and urine in normal premenopausal women. Diseases of the colon \& rectum. 1995;38(11):1206-1209.

75. Fornell EU, Matthiesen L, Sjödahl R, Berg G. Obstetric anal sphincter injury ten years after: subjective and objective long term effects. BJOG: An International Journal of Obstetrics \& Gynaecology. 2005;112(3):312-316.

76. Glazener CM, MacArthur C, Hagen S, Elders A, Lancashire R, Herbison GP, Wilson PD. Twelve-year follow-up of conservative management of postnatal urinary and faecal incontinence and prolapse outcomes: randomised controlled trial. BJOG: An International Journal of Obstetrics \& Gynaecology. 2014;121(1):112-120.

77. MacArthur C, Glazener C, Lancashire R, Herbison P, Wilson D. Exclusive caesarean section delivery and subsequent urinary and faecal incontinence: a 12-year longitudinal study. BJOG: An International Journal of Obstetrics \& Gynaecology. 2011;118(8):1001-1007.

78. Nygaard IE, Rao SS, Dawson JD. Anal incontinence after anal sphincter disruption: a 30-year retrospective cohort study. Obstetrics \& Gynecology. 1997;89(6):896-901. 
79. Bollard RC, Gardiner A, Duthie GS, Lindow SW. Anal sphincter injury, fecal and urinary incontinence. Diseases of the colon \& rectum. 2003;46(8):1083-8.

80. McKinnie V, Swift SE, Wang W, Woodman P, O'boyle A, Kahn M, Valley M, Bland D, Schaffer J. The effect of pregnancy and mode of delivery on the prevalence of urinary and fecal incontinence. American Journal of Obstetrics \& Gynecology. 2005;193(2):512-7.

81. Goldberg RP, Kwon C, Gandhi S, Atkuru LV, Sorensen M, Sand PK. Prevalence of anal incontinence among mothers of multiples and analysis of risk factors. American Journal of Obstetrics \& Gynecology. 2003;189(6):1627-30.

82. Sultan AH, Kamm MA, Hudson CN, Bartram CI. Third degree obstetric anal sphincter tears: risk factors and outcome of primary repair. BMJ. 1994;308(6933):887-891.

83. Haadem K, Ohrlander S, Lingman G. Long-term ailments due to anal sphincter rupture caused by delivery-a hidden problem. European Journal of Obstetrics \& Gynecology and Reproductive Biology. 1988;27(1):27-32.

84. Chaliha C, Kalia V, Stanton SL, Monga AS, Sultan AH. Antenatal prediction of postpartum urinary and fecal incontinence. Obstetrics \& Gynecology. 1999;94(5):689-694.

85. Uustal Fornell EK, Berg G, Haalböök O, Matthiesen LS, Sjödahl R. Clinical consequences of anal sphincter rupture during vaginal delivery. Journal of the American College of Surgeons. 1996;183(6):553-8.

86. Mazouni C, Bretelle F, Battar S, Bonnier P, Gamerre M. Frequency of persistent anal symptoms after first instrumental delivery. Diseases of the colon \& rectum. $2005 \mathrm{Jul}$ 1;48(7):1432-1436. 
87. Tetzschner T, Sorensen M, Lose G, Christiansen J. Anal and urinary incontinence in women with obstetric anal sphincter rupture. International Journal of Gynecology \& Obstetrics. 1997;56(2):222.

88. Haadem K, Ling L, Dahlstrom A, Ohrlander S. Anal sphincter function after delivery rupture. Obstetrics \& Gynecology. 1987;70(1):53-6.

89. Gjessing H, Backe B, Sahlin Y. Third degree obstetric tears; outcome after primary repair. Acta obstetricia et gynecologica Scandinavica. 1998;77(7):736-40.

90. Kumar R. Anal incontinence and quality of life following obstetric anal sphincter injury. Archives of gynecology and obstetrics. 2012;285(3):591-597.

91. Poen AC, Felt-Bersma RJ, Strijers RL, Dekker GA, Cuesta MA, Meuwissen SG. Thirddegree obstetric perineal tear: long-term clinical and functional results after primary repair. British Journal of Surgery. 1998;85(10):1433-1438.

92. Sørensen SM, Bondesen H, Istre O, Vilmann P, Serensen SM. Perineal Rupture Following Vaginal Delivery Long-term Consequences. Acta obstetricia et gynecologica Scandinavica. 1988;67(4):315-318.

93. de Leeuw JW, Vierhout ME, Struijk PC, Auwerda HJ, Bac DJ, Wallenburg HC. Anal sphincter damage after vaginal delivery. Diseases of the Colon \& Rectum. 2002;45(8):1004-10.

94. Sultan AH, Johanson RB, Carter JE. Occult anal sphincter trauma following randomized forceps and vacuum delivery. International Journal of Gynecology \& Obstetrics. 1998;61(2):113-119.

95. Johanson RB, Heycock E, Carter J, Sultan AH, Walklate K, Jones PW. Maternal and child health after assisted vaginal delivery: five-year follow up of a randomised controlled study comparing forceps and ventouse. BJOG: an international journal of obstetrics \& gynaecology. 1999;106(6):544-9. 
96. Kunduru L, Kim SM, Heymen S, Whitehead WE. Factors that affect consultation and screening for fecal incontinence. Clinical Gastroenterology and Hepatology. 2015;13(4):709-716.

97. Belmonte-Montes C, Hagerman G, Vega-Yepez PA, Hernández-de-Anda E, FonsecaMorales V. Anal sphincter injury after vaginal delivery in primiparous females. Diseases of the colon \& rectum. 2001;44(9):1244-8.

98. Meyer S, Schreyer A, De Grandi P, Hohlfeld P. The effects of birth on urinary continence mechanisms and other pelvic-floor characteristics. Obstetrics \& Gynecology. 1998;92(4):613-618.

99. Groutz A, Fait G, Lessing JB, David MP, Wolman I, Jaffa A, Gordon D. Incidence and obstetric risk factors of postpartum anal incontinence. Scandinavian journal of gastroenterology. 1999;34(3):315-8.

100. Farrell SA, Allen VM, Baskett TF. Anal incontinence in primiparas. Journal SOGC. $2001 ; 23(4): 321-6$.

101. Borello-France D, Burgio KL, Richter HE, Zyczynski H, FitzGerald MP, Whitehead W, Fine P, Nygaard I, Handa VL, Visco AG, Weber AM. Fecal and urinary incontinence in primiparous women. Obstetrics \& Gynecology. 2006;108(4):863-72.

102. Yang X, Zhang HX, Yu HY, Gao XL, Yang HX, Dong Y. The prevalence of fecal incontinence and urinary incontinence in primiparous postpartum Chinese women. European Journal of Obstetrics and Gynecology and Reproductive Biology. 2010 Oct $1 ; 152(2): 214-7$

103. Jelovsek JE, Piccorelli A, Barber MD, Tunitsky-Bitton E, Kattan MW. Prediction models for postpartum urinary and fecal incontinence in primiparous women. Female pelvic medicine \& reconstructive surgery. 2013;19(2):110-118. 
104. Crawford LA, Quint EH, Pearl ML, DeLANCEY JO. Incontinence following rupture of the anal sphincter during delivery. Obstetrics \& Gynecology. 1993;82(4):527-531.

105. Lal M, Mann CH, Callender R, Radley S. Does cesarean delivery prevent anal incontinence?. Obstetrics \& Gynecology. 2003;101(2):305-12.

106. Brincat C, Lewicky-Gaupp C, Patel D, Sampselle C, Miller J, DeLancey JO, Fenner DE. Fecal incontinence in pregnancy and post partum. International Journal of Gynecology \& Obstetrics. 2009;106(3):236-8.

107. Lipschuetz M, Cohen SM, Liebergall-Wischnitzer M, Zbedat K, Hochner-Celnikier D, Lavy Y, Yagel S. Degree of bother from pelvic floor dysfunction in women one year after first delivery. European Journal of Obstetrics and Gynecology and Reproductive Biology. 2015;191:90-4

108. Sultan AH, Kamm MA, Hudson CN, Thomas JM, Bartram CI. Anal-sphincter disruption during vaginal delivery. New England journal of medicine. 1993;329(26):1905-1911.

109. Sultan AH, Kamm MA, Hudson CN. Pudendal nerve damage during labour: prospective study before and after childbirth. BJOG: An International Journal of Obstetrics \& Gynaecology. 1994;101(1):22-28.

110. Tetzschner T, Sørensen M, Jønsson L, Lose G, Christiansen J. Delivery and pudendal nerve function. Acta obstetricia et gynecologica Scandinavica. $1997 ; 76(4): 324-331$.

111. Baydock SA, Flood C, Schulz JA, MacDonald D, Esau D, Jones S, Hiltz CB. Prevalence and risk factors for urinary and fecal incontinence four months after vaginal delivery. Journal of obstetrics and gynaecology Canada. 2009;31(1):36-41.

112. MacArthur C, Bick DE, Keighley MR. Faecal incontinence after childbirth. BJOG: An International Journal of Obstetrics \& Gynaecology. 1997;104(1):46-50. 
113. Sørensen M, Tetzschner T, Rasmussen 0Ø, Bjarnesen J, Christiansen J. Sphincter rupture in childbirth. British journal of surgery. 1993;80(3):392-394.

114. Walsh CJ, Mooney EF, Upton GJ, Motson RW. Incidence of third-degree perineal tears in labour and outcome after primary repair. British journal of surgery. 1996;83(2):218-21.

115. Laine K, Skjeldestad FE, Sanda B, Horne H, Spydslaug A, Staff AC. Prevalence and risk factors for anal incontinence after obstetric anal sphincter rupture. Acta obstetricia et gynecologica Scandinavica. 2011;90(4):319-24.

116. Size EH. Prevalence and severity of anal incontinence in women with and without additional vaginal deliveries after a fourth-degree perineal laceration. Diseases of the colon \& rectum. 2005 Jan 1;48(1):66-9

117. Sangalli MR, Floris L, Faltin D, Weil A. Anal incontinence in women with third or fourth degree perineal tears and subsequent vaginal deliveries. Australian and New Zealand Journal of Obstetrics and Gynaecology. 2000;40(3):244-248.

118. Size EH. Anal incontinence among women with one versus two complete thirddegree perineal lacerations. International Journal of Gynecology \& Obstetrics. 2005 Sep 1;90(3):213-7.

119. Sultan AH, Kamm MA, Bartram CI, Hudson CN. Anal sphincter trauma during instrumental delivery. International Journal of Gynecology \& Obstetrics. $1993 ; 43(3): 263-270$

120. Rasmussen JL, Ringsberg KC. Being involved in an everlasting fight-a life with postnatal faecal incontinence. A qualitative study. Scandinavian journal of caring sciences. 2010;24(1):108-115. 
121. Heymen S, Palsson O, Simren M, Whitehead WE. Patient preferences for endpoints in fecal incontinence treatment studies. Neurogastroenterology \& Motility. 2017;29:e13032

122. Sultan AH. Obstetrical perineal injury and anal incontinence. Clinical Risk. 1999;5(6):193-196.

123. Patterns of maternity care in English NHS Hospitals 2013/2014. Available at: https://www.rcog.org.uk/en/guidelines-research-services/audit-qualityimprovement/clinical-indicators-project/ Accessed 20 Jan 2018.

124. Gurol-Urganci I, Cromwell DA, Edozien LC, Mahmood TA, Adams EJ, Richmond DH, et al. Third- and fourth-degree perineal tears among primiparous women in England between 2000 and 2012: time trends and risk factors. BJOG 2013;120:15161525

125. The OASI Care Bundle Project. Royal College of Obstetricians and Gynaecologists. Available at: https://www.rcog.org.uk/OASICareBundle Accessed 20 Jan 2018.

126. Poulsen Mø, Madsen ML, Skriver-Møller AC, Overgaard C. Does the Finnish intervention prevent obstetric anal sphincter injuries? A systematic review of the literature. BMJ open. 2015;5(9):e008346.

127. Bachman JW (2003) The Patient-Computer Interview: A Neglected Tool That Can Aid the Clinician. Mayo Clin Proceed 78: 67-78.

128. Gray T, Li W, Campbell P et al. Evaluation of coital incontinence by electronic questionnaire: prevalence, associations and outcomes in women attending a urogynaecology clinic. Int Urogynecolgy Jounral (2017). https://doi.org/10.1007/s00192-017-3380-x 
129. Rockwood TH, Church JM, Fleshman JW, Kane RL, Mavrantonis C, Thorson AG, Wexner SD, Bliss D, Lowry AC. Fecal incontinence quality of life scale. Diseases of the Colon \& Rectum. 2000 Jan 31;43(1):9-16.

130. Vaizey CJ, Carapeti E, Cahill JA, Kamm MA. Prospective comparison of faecal incontinence grading systems. Gut. 1999;44(1):77-80.

131. Barber MD, Kuchibhatla MN, Pieper CF, Bump RC. Psychometric evaluation of 2 comprehensive condition-specific quality of life instruments for women with pelvic floor disorders. American journal of obstetrics and gynecology. 2001 Dec 31;185(6):1388-95.

132. Due U, Ottesen M. The Danish anal sphincter rupture questionnaire: validity and reliability. Acta obstetricia et gynecologica Scandinavica. 2009 Jan 1;88(1):36-42.

133. Maeda Y, Vaizey CJ, Norton C. St. Mark's Incontinence Score. Diseases of the Colon \& Rectum. 2007 Dec 1;50(12):2252-.

134. Browning GG, Parks AG. Postanal repair for neuropathic faecal incontinence: correlation of clinical result and anal canal pressures. British Journal of Surgery. $1983 ; 70(2): 101-4$

135. Talley NJ, Newman P, Boyce PM, Paterson KJ, Owen BK. Initial validation of a bowel symptom questionnaire* and measurement of chronic gastrointestinal symptoms in Australians. Australian and New Zealand journal of medicine. 1995;25(4):302-8. 
136. Reilly WT, Talley NJ, Pemberton JH, Zinsmeister AR. Validation of a questionnaire to assess fecal incontinence and associated risk factors. Diseases of the colon \& rectum. 2000;43(2):146-53.

137. Pescatori M, Anastasio G, Bottini C, Mentasti A. New grading and scoring for anal incontinence. Diseases of the colon \& rectum. 1992;35(5):482-487.

138. Bugg GJ, Kiff ES, Hosker G. A new condition-specific health-related quality of life questionnaire for the assessment of women with anal incontinence. BJOG: An International Journal of Obstetrics \& Gynaecology. 2001;108(10):1057-1067.

139. Kwon S, Visco AG, Fitzgerald MP, Ye W, Whitehead WE, Pelvic Floor Disorders Network. Validity and reliability of the Modified Manchester Health Questionnaire in assessing patients with fecal incontinence. Diseases of the colon \& rectum. 2005;48(2):323-334.

140. Baessler K, O’Neill SM, Maher CF, Battistutta D. Australian pelvic floor questionnaire: a validated interviewer-administered pelvic floor questionnaire for routine clinic and research. International Urogynecology Journal. 2009;20(2):149-58.

141. Lukacz ES, Lawrence JM, Buckwalter JG, Burchette RJ, Nager CW, Luber KM. Epidemiology of prolapse and incontinence questionnaire: validation of a new epidemiologic survey. International Urogynecology Journal. 2005;16(4):272-84.

142. Hiller L, Radley S, Mann CH, Radley SC, Begum G, Pretlove SJ, Salaman JH. Development and validation of a questionnaire for the assessment of bowel and 
lower urinary tract symptoms in women. BJOG: An International Journal of Obstetrics \& Gynaecology. 2002 Apr 1;109(4):413-423.

143. Radley SC, Jones GL, Tanguy EA, Stevens VG, Nelson C, Mathers NJ. Computer interviewing in urogynaecology: concept, development and psychometric testing of an electronic pelvic floor assessment questionnaire in primary and secondary care. BJOG: An International Journal of Obstetrics \& Gynaecology. 2006;113(2):231-238.

144. Dowrick AS, Wootten AC, Murphy DG, Costello AJ. “We used a validated questionnaire": what does this mean and is it an accurate statement in urologic research?. Urology. 2015 Jun 1;85(6):1304-11.

\section{Tables and figures, including legends}

Figure 1: PRISMA diagram showing selection of articles for review.

Supplementary Table 1: Summary of results for studies using validated patient reported outcome measures or symptom scales to identify anal incontinence after childbirth, including the language in which each study was undertaken.

Supplementary Table 2: Summary of results for studies using non-validated questionnaires to identify anal incontinence after childbirth.

Supplementary Table 3: Summary of results for studies using patient interviews to identify faecal incontinence after childbirth.

Table 1: List of validated patient reported outcome measures or symptom scales identified in this systematic review, including other languages of validation these measures are available in

Supplementary Table 4: Response rates for different follow up periods.

Table 2: Comparison of faecal incontinence type and response rates for nonpersonalised (PROM/questionnaire) and personalised (interview) modalities at different times of follow up. 
Table 3: Comparison of mean prevalence rates reported for anal incontinence using validated questionnaires/symptom scales or patient interview

Table 4: Comparison of mean prevalence rates reported for anal incontinence using non-validated questionnaires/symptom scales or patient interview

Table 5: Comparison of mean prevalence rates reported for anal incontinence using validated questionnaires/symptom scales or non-validated questionnaires 